\title{
Biofilm production by multiresistant Corynebacterium striatum associated with nosocomial outbreak
}

\author{
Cassius de Souza', Yuri Vieira Faria', Lincoln de Oliveira Sant'Anna', Vanilda Gonçalves Viana', \\ Sérgio Henrique Seabra², Mônica Cristina de Souza', Verônica Viana Vieira ${ }^{3}$, \\ Raphael Hirata Júnior ${ }^{1}$, Lílian de Oliveira Moreira ${ }^{4} /{ }^{+}$, Ana Luíza de Mattos-Guaraldi ${ }^{1}$
}

\author{
'Laboratório de Difteria e Corinebactérias de Importância Clínica, Centro Colaborador de Referência e Pesquisa em Difteria/Fundação \\ Nacional de Saúde/Ministério da Saúde, Universidade do Estado do Rio de Janeiro, Rio de Janeiro, RJ, Brasil \\ ${ }^{2}$ Laboratório de Tecnologia em Bioquímica e Microscopia, Centro Universitário Estadual da Zona Oeste, Rio de Janeiro, RJ, Brasil \\ ${ }^{3}$ Laboratório de Genética Molecular de Microrganismos, Instituto Oswaldo Cruz-Fiocruz, Rio de Janeiro, RJ, Brasil \\ ${ }^{4}$ Laboratório de Bacteriologia e Imunologia Clínica, Universidade Federal do Rio de Janeiro, Rio de Janeiro, RJ, Brasil
}

Corynebacterium striatum is a potentially pathogenic microorganism that causes nosocomial outbreaks. However, little is known about its virulence factors that may contribute to healthcare-associated infections (HAIs). We investigated the biofilm production on abiotic surfaces of multidrug-resistant (MDR) and multidrug-susceptible $(M D S)$ strains of C. striatum of pulsed-field gel electrophoresis types I-MDR, II-MDR, III-MDS and IV-MDS isolated during a nosocomial outbreak in Rio de Janeiro, Brazil. The results showed that $\mathrm{C}$. striatum was able to adhere to hydrophilic and hydrophobic abiotic surfaces. The C. striatum 1987/I-MDR strain, predominantly isolated from patients undergoing endotracheal intubation procedures, showed the greatest ability to adhere to all surfaces. C. striatum bound fibrinogen to its surface, which contributed to biofilm formation. Scanning electron microscopy showed the production of mature biofilms on polyurethane catheters by all pulsotypes. In conclusion, biofilm production may contribute to the establishment of HAIs caused by C. striatum.

Key words: biofilm - Corynebacterium striatum - epidemic clone - fibrinogen - multi-resistance - nosocomial outbreak

Corynebacterium striatum is an emerging multidrugresistant (MDR) potentially pathogenic microorganism that causes nosocomial infection in patients who have experienced long hospital admissions, those who have received several courses of antibiotics (Camello et al. 2003, Otsuka et al. 2006, Renom et al. 2007, Baio et al. 2013), those with acquired immune deficiency syndrome (AIDS) or cancer and those who have received a transplant (Tarr et al. 2003, Martins et al. 2009). Cases of severe infections in both immunocompromised and immunocompetent individuals and nosocomial outbreaks due to MDR C. striatum are increasing in both industrialised and developing countries. C. striatum has been associated with cases of pulmonary infections, sepsis, endocarditis, meningitis, osteomyelitis, arthritis, sinusitis, skin wounds and intrauterine infections (Rufael \& Cohn 1994, Weiss et al. 1996, Fernández-Ayala et al. 2001, Camello et al. 2003, Renom et al. 2007, Scholle 2007, Boltin et al. 2009, Campanile et al. 2009, Martins et al. 2009, Moore et al. 2010, Oliva et al. 2010, Baio et al. 2013).

doi: 10.1590/0074-02760140373

Financial support: CAPES (E26/101.937/2009), FAPERJ

(E26/110.735/2012), CNPq (300236/2010-7),

SR-2/UERJ, PNPD-CAPES/MEC (0370088)

+ Corresponding author: lilian@pharma.ufrj.br

Received 10 October 2014

Accepted 29 January 2015
Genotyping analysis by pulsed-field gel electrophoresis (PFGE) has identified PFGE types associated with nosocomial outbreaks of respiratory origin and with resistance to a broad range of antibiotics (MDR phenotype). In Italy, MDR C. striatum isolates have been recovered from hospitalised patients who have undergone surgery or have been admitted to intensive care units (ICUs). These isolates have been responsible for cases of ventilator-associated pneumonia and tracheobronchitis, catheter-related sepsis and wound infections. Infections caused by this species have been strongly associated with devices, including not only tubes and catheters, but also sternal surgical wound wires (Campanile et al. 2009). C. striatum has also been isolated from other materials for hospital use, such as endotracheal tubes (MartinezMartinez et al. 1995). Earlier genotype studies have confirmed that $C$. striatum may be transmitted between patients, from person to person and via caretakers (Leonard et al. 1994). Recently, a nosocomial outbreak caused by C. striatum was documented in Rio de Janeiro (RJ), Brazil. PFGE analysis indicated the presence of four PFGE profiles, including two related clones of MDR strains (PFGE I and II). The results of these studies demonstrate the predominance of PFGE-type I MDR isolates that are mainly isolated from ICUs and surgical wards. C. striatum strains have largely been isolated in pure culture from tracheal aspirates of patients undergoing endotracheal intubation procedures (Baio et al. 2013).

Currently, more than half of the infectious diseases that affect mildly immunocompromised patients involve bacterial species that are commonly encountered in the environment or constitute the body's normal flora, including 
TABLE

Origin and pulsed-field gel electrophoresis (PFGE)-types of partially studied Corynebacterium striatum strains isolated from patients during a nosocomial outbreak in the metropolitan area, Rio de Janeiro, Brazil used in this study

\begin{tabular}{|c|c|c|c|c|c|c|}
\hline Strains/year & $\begin{array}{l}\text { Gender/ } \\
\text { age }\end{array}$ & $\begin{array}{l}\text { Hospital } \\
\text { wards }\end{array}$ & $\begin{array}{l}\text { Isolation } \\
\text { site }\end{array}$ & Outcome & $\begin{array}{c}\text { Antimicrobial } \\
\text { susceptibility patterns }\end{array}$ & $\begin{array}{l}\text { PFGE- } \\
\text { types }\end{array}$ \\
\hline 1987 BR-RJ/09 & $\mathrm{F} / 50$ & Nursery 18 & BAL & Death & MDR & I \\
\hline 2369 BR-RJ/09 & $\mathrm{M} / \mathrm{NI}$ & General ICU & TA & Cure & MDR & II \\
\hline 1961 BR-RJ/09 & $\mathrm{F} / 37$ & Infectious diseases & Urine & $\mathrm{NI}$ & MDS & III \\
\hline 1954 BR-RJ/09 & $\mathrm{M} / \mathrm{NI}$ & Thoracic MSU & Surgical wound & NI & MDS & IV \\
\hline
\end{tabular}

BAL: bronchoalveolar lavage; F: female; ICU: intensive care unit; M: male; MDR: multiresistance ( $\geq 3$ types of antimicrobial agents); MDS: multidrug susceptible; MSU: medical surgical unit; NI: not informed; TA: tracheal aspirate;

several corynebacterial species (Martins et al. 2009). Opportunistic pathogens may be endowed with an array of virulence factors that facilitate their ability to survive within host tissues and confer resistance to clearance by host immune mechanisms and antimicrobial killing. The ability to form biofilms may be a prerequisite for the pathogeneses of nosocomial diseases associated (or not) with the use of medical devices (Bonifait et al. 2008). Biofilms have been previously described in Corynebacterium diphtheriae, Corynebacterium pseudotuberculosis, Corynebacterium renale, Corynebacterium urealyticum and Corynebacterium jeikeium (Mattos-Guaraldi \& Formiga 1991, Soriano et al. 1993, Mattos-Guaraldi et al. 1999a, b, Olson et al. 2002, Kwaszewska et al. 2006, Gomes et al. 2009, 2013, Soriano et al. 2009). Thus, the better recognition and understanding of the biology and virulence potential of $C$. striatum strains may help to effectively prevent infections caused by them. Therefore, we investigated the in vitro capacities for biofilm formation of $C$. striatum strains representative of four different PFGE types isolated during a nosocomial outbreak in RJ (Baio et al. 2013).

\section{SUBJECTS, MATERIALS AND METHODS}

Bacterial strains - Table shows the epidemiological and microbiological features of the partially studied $C$. striatum strains used in this investigation (Baio et al. 2013). C. striatum identification was established by $16 S$ $r R N A$ and $r p o B$ gene sequencing. C. striatum pulsotypes I and II exhibited MDR profiles showing susceptibility only to vancomycin, linezolid and tetracycline, while $C$. striatum pulsotypes III and IV showed susceptibility to most of the 21 antimicrobial agents tested and resistance only to fosfomycin and ticarcillin/clavulanate. The $C$. diphtheriae CAT5003748 strain was used as a positive control in all experiments (Gomes et al. 2009).

Biofilm formation on hydrophilic surfaces of glass tubes - Microorganisms were inoculated in glass tubes $(13 \times 100 \mathrm{~mm})$ containing $4 \mathrm{~mL}$ of trypticase soy broth (TSB) and incubated at $37^{\circ} \mathrm{C}$ for $24 \mathrm{~h}$ without shaking. The tubes were gently shaken and supernatants with nonadherent bacterial cells were discarded. TSB $(4 \mathrm{~mL})$ was then added and the tubes were reincubated at $37^{\circ} \mathrm{C}$ for $24 \mathrm{~h}$. This procedure was repeated twice. Glass-adherent bacteria created a confluent coat of cells on the sides of the tube. Quantitative analysis of viable sessile cells was based on previously described methods (Mattos-Guaraldi \& Formiga 1991, Dooley et al. 1996).

Quantitative and semiquantitative analyses of biofilm formation on catheter - Polyurethane 16-gauge percutaneous nephrostomy catheters (Intracath; Deseret Pharmaceutical Co, USA) were used for an evaluation of bacterial adherence and biofilm formation on catheter surfaces. Sterile 4-cm segments of polyurethane catheters were immersed in TSB containing $10^{6}$ colony-forming unit (CFU) $\mathrm{mL}^{-1}$ and incubated at $37^{\circ} \mathrm{C}$ for $24 \mathrm{~h}$ (Gomes et al. 2009). Then, quantitative catheter culturing (Dooley et al. 1996) and a semiquantitative roll-plate technique (Maki et al. 1977) were performed using Columbia agar medium supplemented with $5 \%$ sheep blood at $37^{\circ} \mathrm{C}$ for $24 \mathrm{~h}$.

Scanning electron microscopy (SEM) - Sections of glass coverslips and polyurethane catheters were fixed in $2.5 \%$ glutaraldehyde, post-fixed in $1 \%$ osmium tetroxide and dehydrated in a graded series of ethanol. Subsequently, catheter segments were subjected to critical point drying with carbon dioxide, covered with a $10 \mathrm{~nm}$ layer of gold palladium and examined with a JEOL JSM 5310 scanning electron microscope. Sterile unused polyurethane catheters were also processed by SEM directly upon removal from commercial packaging (Gomes et al. 2009).

Biofilm formation on hydrophobic polystyrene surfaces - Biofilm formation on negatively charged polystyrene surfaces was determined quantitatively in 96-well flat-bottomed microtitre plates according to previously described methods (Stepanovic et al. 2000, Gomes et al. 2009). Aliquots of $200 \mu \mathrm{L}$ of bacterial suspensions [0.2 optical density (OD) at $\lambda=570 \mathrm{~nm}]$ were added to the microplate wells. After incubation at $37^{\circ} \mathrm{C}$ for $24 \mathrm{~h}$, the contents of each well were aspirated and washed three times with $200 \mu \mathrm{L}$ phosphate-buffered saline (0.01 M, pH 7.2). The remaining attached bacteria were fixed with $200 \mu \mathrm{L}$ of $99 \%$ methanol and stained with $2 \%$ crystal violet. The negative controls contained TSB only. The bound dye was then solubilised with $160 \mu \mathrm{L}$ of $33 \%$ glacial acetic acid and the OD of the solution was measured at $\lambda=570 \mathrm{~nm}$ using an enzyme immunosorbent assay reader (BioRad, 


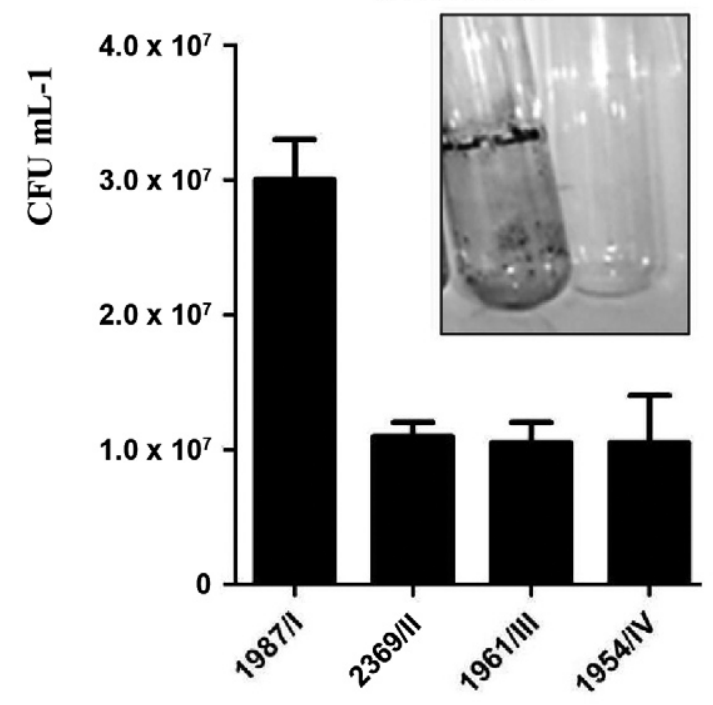

Fig. 1: Corynebacterium striatum adherence to glass surfaces (24 h incubation) evaluated by quantitative and semiquantitative tests. In detail, glass tubes with 1987/I strain exhibiting confluent coat of sessile forms on the surface of glass tube wall and with negative control (trypticase soy broth medium without bacteria). CFU: colony-forming unit.

model 550). The cut-off OD (OD) was defined as the mean OD of the negative control. All strains were classified into the following categories based on the ODs of the bacterial films: nonadherent $\left(0: \mathrm{OD} \leq \mathrm{OD}_{\mathrm{c}}\right)$ or weakly $(+$ : $\left.\mathrm{OD}_{\mathrm{c}}<\mathrm{OD} \leq 2 \times \mathrm{OD}\right)$, moderately $\left(++: 2 \times \mathrm{OD}_{\mathrm{c}}<\mathrm{OD} \leq 4\right.$ $\left.\mathrm{x} \mathrm{OD}_{\mathrm{c}}\right)$ or strongly $\left(+++: 4 \mathrm{x} \mathrm{OD}_{\mathrm{c}} \leq \mathrm{OD}\right)$ adherent.

Influence of fibrinogen (Fbg) on biofilm formation - Biofilm formation $(24 \mathrm{~h})$ was determined in 96-well flat-bottom polystyrene microtitre plates as described above, with some modifications. In these experiments, the wells of the microplates were pre-treated (or not) with human plasmatic Fbg (Sigma Chemical Co, USA) at a concentration of $50 \mu \mathrm{g} \mathrm{mL}^{-1}$ overnight at $4^{\circ} \mathrm{C}$. Fbgcoated wells containing $200 \mu \mathrm{L}$ of TSB medium without bacteria were used as negative controls (Lembke et al. 2006, Gomes et al. 2009).

Statistical analysis - Each experiment was carried out in triplicate and repeated three times. The biofilm formation by each representative pulsotype strain was compared by ANOVA with Tukey's post test. Student's $t$ test was used to compare the means of biofilm formation (OD) in the presence of Fbg for each pulsotype and a $p<0.05$ was considered to be statistically significant. Statistical analyses were performed using GraphPad Prism v.6 (USA).

\section{RESULTS}

Bacterial adherence to hydrophilic surface of glass tube - Successful bacteria may survive in the hospital environment due to their ability to adhere to different substrates. To determine whether C. striatum is able to adhere to glass, we quantified the amount of viable sessile forms of bacteria associated with glass. Viable sessile bacterial cells were observed on glass surfaces at 48 $\mathrm{h}$ post-incubation with $C$. striatum strains of PFGE types

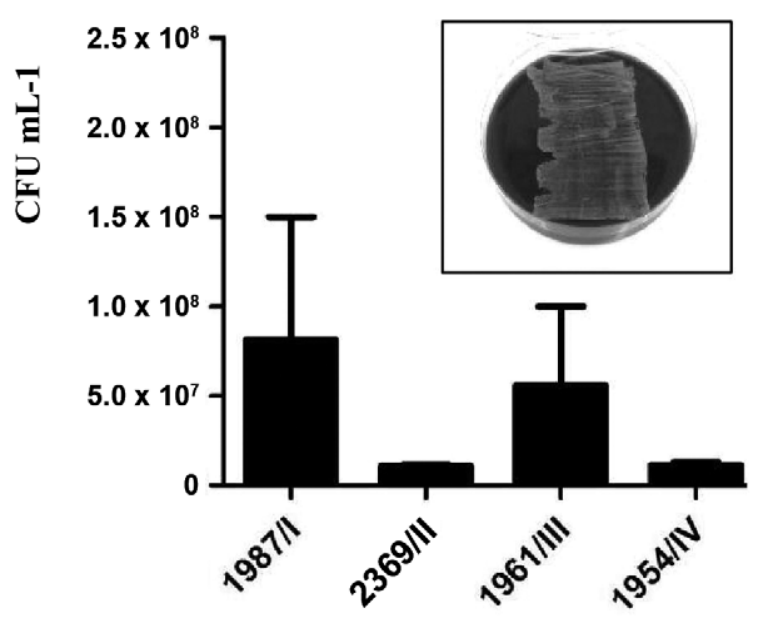

Fig. 2: Corynebacterium striatum adherence to polyurethane surfaces evaluated by quantitative and semiquantitative tests. In detail, 1987/I strain infected catheter segment cultured on blood agar plates (roll plate technique). CFU: colony-forming unit.

I, II, III and IV at different levels (Fig. 1). In Fig. 1, a representative side figure illustrates sessile bacteria stained with crystal violet, indicating the formation of a positive slime/biofilm on the glass surface. All strains were able to strongly adhere to the glass surface, however the $C$. striatum 1987/I-MDR strain showed the highest ability to adhere to this hydrophilic abiotic surface $(\mathrm{p}<0.05)$.

Biofilm formation on polyurethane catheter surface - The ability to adhere to catheter materials for intravenous use and medical devices inserted into the body are important characteristics of bacteria associated with healthcare-associated infections. To determine whether C. striatum is able to adhere and form biofilms on catheter surfaces, segments of polyurethane catheters were colonised in vitro by C. striatum 1987/I, 2369/II, 1961/III and 1954/IV strains. The evaluation of the adherence and viability of microorganisms on the polyurethane catheter segments by the semiquantitative roll plate method $(>15$ $\mathrm{CFU})$ and by quantitative catheter culture assays $(>1.5$ x $10^{6} \mathrm{CFU}$ ) showed that viable $C$. striatum cells were extensively adherent to and multiplied on the polyurethane catheter surface (Fig. 2). In Fig. 2A, the representative side figure illustrates bacterial growth on an agar plate after catheter colonisation, as assessed by the roll-plate technique. Although all strains were able to adhere to the catheter surface, the $C$. striatum 1987/I-MDR strain again exhibited significantly greater adherence $(p<0.05)$ to this abiotic hydrophobic surface compared with the representative strains of pulsotypes II, III and IV.

Morphological aspects of biofilm formation on the surface of polyurethane medical device as evaluated by SEM - After determining that C. striatum was able to adhere to glass and catheter surfaces, forming a visible biofilm, the morphological aspects of the biofilm were inves- 

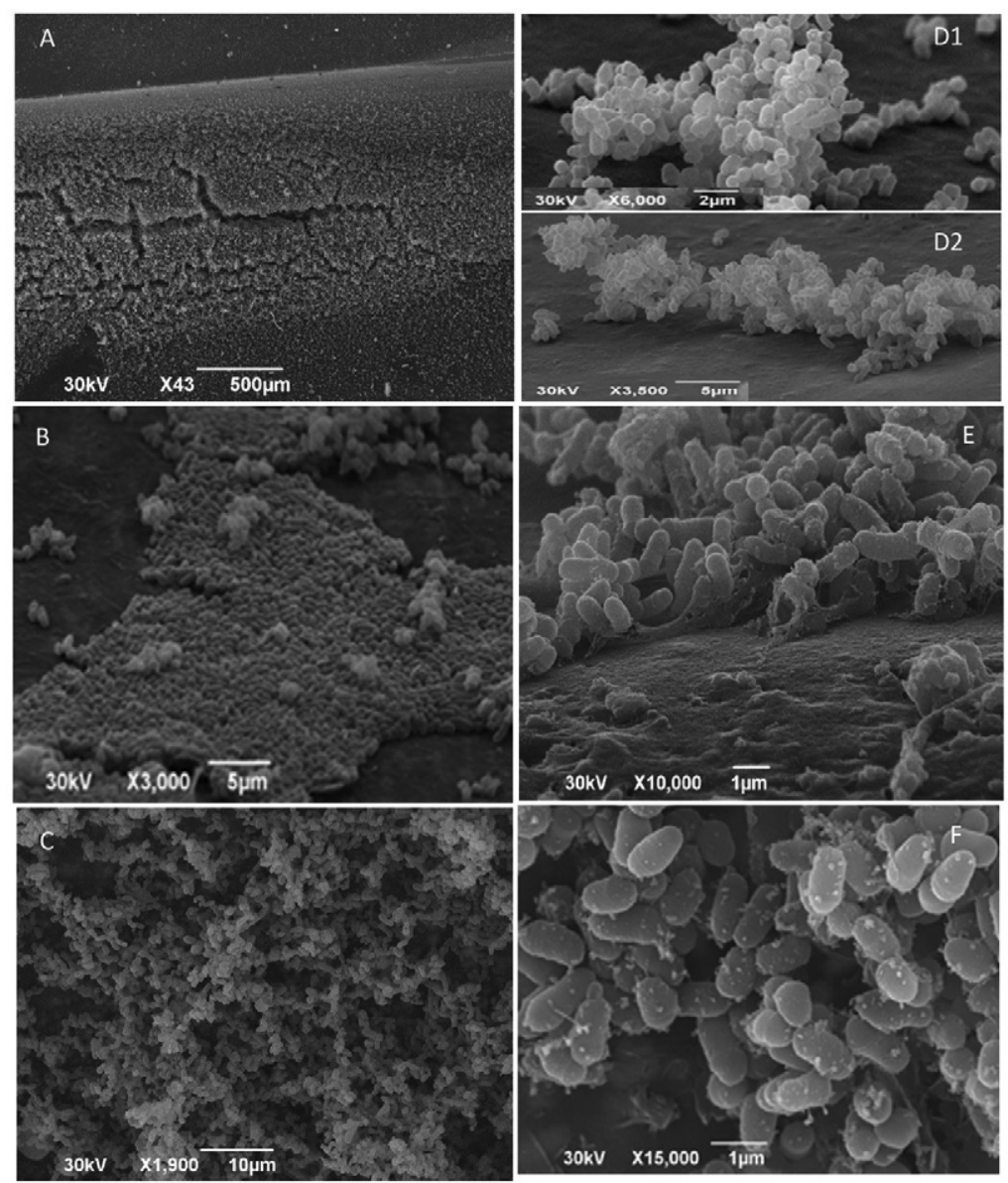

Fig. 3: scanning electron micrographs illustrating biofilm formation on polyurethane catheter surfaces after $24 \mathrm{~h}$ incubation with different Corynebacterium striatum strains. Pulsed-field gel electrophoresis (PFGE)-types I-IV: A, C, F: 1987/I; B, E: 2369/II; D1: 1961/III; D2: 1954/IV; A-C: a large amount of biofilm material exhibiting; B, D: bacterial microcolonies; E: amorphous material on the catheter surface is evident; C, F: presence of hollow voids indicative of mature biofilm formation on surfaces of polyurethane catheters.

tigated by SEM. SEM assay confirmed that all C. striatum strains were able to colonise the polyurethane catheter and form mature biofilms (Fig. 3). Fig. 3A-C shows the large amount of biofilm material that was observed. Bacterial microcolonies were present (Fig. 3B, D) and amorphous material on the catheter surface was evident (Fig. 3E). In addition, hollow voids were present (Fig. 3C, F). The presence of autoaggregative microcolonies, extracellular slime and hollow voids on the polyurethane surface were all indicative of mature biofilm structure.

Bacterial adherence to hydrophobic polystyrene surface and influence of Fbg on biofilm formation - In addition to glass and catheter surfaces, we also investigated the ability of $C$. striatum to adhere to plastic using negatively charged polystyrene 96 -well flat-bottom microtitre plates. The quantification of biofilm revealed that all C. striatum strains of PFGE types I, II, III and IV were able to adhere to the negatively charged plastic (polystyrene) surface at different intensities (Fig. 4). Again, the C. striatum 1987/I-MDR strain exhibited a significantly $(p<0.05)$ greater level of adherence to this abiotic hydrophobic surface compared with the C. striatum 2369/II-MDR, 1961/III-multidrug-susceptible (MDS) and 1954/IV-MDS strains.

Several microorganisms use extracellular matrix proteins, such as Fbg, to increase their ability to interact with different cells and also with abiotic surfaces. To investigate the influence of Fbg on the ability of C. striatum to adhere to plastic microtitre plates, plates were pre-treated with human plasmatic Fbg prior to bacterial colonisation. As shown in Fig. 4, human Fbg enhanced biofilm formation on the polystyrene surfaces by the $C$. striatum 1987/I-MDR ( $\mathrm{p}=0.00362), 2369 / \mathrm{II}-\mathrm{MDR}(\mathrm{p}=$ $0.0022)$ and $1961 /$ III-MDS $(p=0.0105)$ strains, suggesting that this matrix protein may contribute to the interaction of different clones of this human pathogen with abiotic hydrophobic surfaces.

\section{DISCUSSION}

Bacterial biofilms form in association with many human activities, including food processing, transportation, public infrastructure and, most importantly, healthcare (Rzhepishevska et al. 2013). Biofilms have been found on 


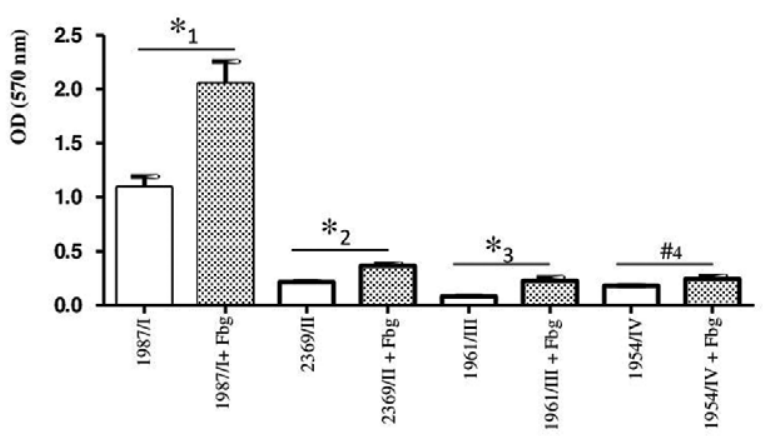

Fig. 4: biofilm formation ( $24 \mathrm{~h}$ incubation) on polystyrene surface by Corynebacterium striatum strains evaluated by a semiquantitative microplate assay. Effect of human plasma fibrinogen (Fbg) on biofilm formation by representative strains of pulsed-field gel electrophoresis (PFGE)-types I-IV. Experiments were performed in triplicate and the means standard deviations of three independent experiments. *: $\mathrm{p}<0.05 ; \#: \mathrm{p}>0.05$.

numerous medical devices (e.g., urinary catheters, central venous catheters and endoscopes). Their presence can have serious implications for immunocompromised patients and those with indwelling medical devices (Brown \& Williams 1985, Russell \& Russell 1995, Rutala et al. 2008, Al Akhrass et al. 2012). The acquisition of the ability to form biofilms may represent a good strategy for a microorganism to acquire enhanced survival under conditions of stress, e.g., during host invasion or following antibiotic treatment, because cells growing in biofilms are highly resistant to components of the human immune system and to numerous types of antimicrobial agents. In addition, the ability of bacterial cells to transfer genes horizontally is enhanced within biofilm communities, thereby facilitating the spread of antibiotic resistance (Stewart \& Costerton 2001, Lee et al. 2008).

Our results reveal the capacities of diverse $C$. striatum isolates to adhere to various abiotic surfaces and to form biofilms in an in vitro catheter model. The data revealed variations among the capacities of diverse clones of MDR and MDS C. striatum strains identified during a nosocomial outbreak in $\mathrm{RJ}$ to adhere to and survive on positively and negatively charged abiotic surfaces. Notably, we identified an association of increased biofilm formation, antimicrobial multiresistance and clonality of the $C$. striatum strains. In the present study, $C$. striatum MDR PFGE types I and II were predominantly isolated during the nosocomial outbreak from in-patients undergoing endotracheal intubation procedures in the ICU or in surgical wards. The clinical isolates of these PFGE types expressed a high capacity to form biofilms on hydrophilic (glass; positively charged) and hydrophobic (polystyrene; negatively charged) abiotic surfaces, including polyurethane (positively charged) catheter surfaces.

The C. striatum strains showed properties similar to other pathogenic biofilm producers. The results of the semiquantitative roll-plate method and quantitative catheter culture assays showed that viable bacterial cells extensively adhered to and multiplied on the surfaces of polyurethane catheters. SEM revealed a large amount of biofilm on polyurethane catheter surfaces produced by all $C$. striatum strains tested.

The developmental biology of biofilm formation can be characterised into three stages: initial attachment, development of microcolony formation and detachment (O'Toole et al. 2000). Similar to C. diphtheriae (Gomes et al. 2013), Acinetobacter baumannii (Rao et al. 2008) and other nondiphtherial Corynebacterium species (Soriano et al. 1993, Gomes et al. 2009), autoaggregative C. striatum strains were able to attach to and form microcolonies (a hallmark of biofilm formation) on abiotic surfaces. C. striatum also formed matrix-enclosed microcolonies on in vitro colonised polyurethane surfaces. Hollow voids indicative of mature biofilm formation on the surfaces of polyurethane catheters were also observed. The formation of hollow voids seems to be involved in the dispersion of sessile bacterial cells during the final stage of biofilm formation, which can increase bacterial virulence (Rice et al. 2009).

Some bacterial properties are associated with biofilm production, including the increased synthesis of exopolysaccharides, hydrophobic properties and the development of antibiotic resistance (Olson et al. 2002, Costerton et al. 2003, Rao et al. 2008). A previous study has addressed the prevention of biofilms and has shown that the surface charge of an abiotic substrate may influence the morphology and physiology of a biofilm (Rzhepishevska et al. 2013). In the present study, the MDR and MDS C. striatum strains were able to adhere at different levels to negatively charged plastic (polystyrene) and positively charged (glass) surfaces, as previously observed with $C$. diphtheriae and/or C. urealyticum (Mattos-Guaraldi \& Formiga 1991, Mattos-Guaraldi et al. 1999a, b, Soriano et al. 2009, Gomes et al. 2013). Polyurethane implanted subcutaneously into mice led to an infiltration of erythrocytes and subsequent haemolysis, possibly due to the attraction of this positively charged plastic to negatively charged cells (Rigdon 1970). In accordance with previous observations of C. diphtheriae (Mattos-Guaraldi \& Formiga 1991, Mattos-Guaraldi et al. 1999a, b, Gomes et al. 2013), the negatively charged cell surfaces of $C$. striatum strains and their adherence to polyurethane may be partially explained by the positive electric charge associated with this polymer. Moreover, the amorphous deposited substances or glycocalyx noted surrounding $C$. striatum microcolonies on the surfaces of the polyurethane catheters suggest that this bacteria may produce or attract substances that strengthen their attachment to inert surfaces in vitro.

Hydrophobicity has been significantly associated with biofilm formation of lipophilic skin corynebacteria on solid surfaces (Kwaszewska et al. 2006). For C. diphtheriae strains, bacterial autoaggregation and hydrophobicity are mainly related to biofilm formation on polystyrene surfaces (Mattos-Guaraldi et al. 1999a). The cell surface hydrophobicity of $C$. striatum strains was demonstrated by their ability to adhere to polystyrene surfaces. Therefore, $C$. striatum strains should be included among bacterial species that have a natural tendency to adhere to available biotic and/or abiotic surfaces and to 
form biofilm (Olson et al. 2002, Kwaszewska et al. 2006, Soriano et al. 2009) and that are also capable of rapid physiological responses following exposure to surfaces with varying physicochemical characteristics, enabling some bacterial colonisation on negatively charged surfaces (Kwaszewska et al. 2006).

In natural environments, bacteria typically adhere to the layer of adsorbed molecules that coats inert surfaces, the so-called "conditioning film" and not directly to the substratum. In vivo, any material surface is rapidly covered by plasma and matrix proteins, to which bacteria may display specific adhesins. The stimulation of bacterial biofilm formation by exogenous mammalian proteins has been reported for many human pathogens (Bonifait et al. 2008, Gomes et al. 2009, 2013). Fbg is a major protein in human plasma and is primarily involved in the coagulation cascade system through its conversion to insoluble fibrin. Fbg synthesis is dramatically upregulated during inflammation or under stress conditions, such as systemic infections. Fbg and fibrin play overlapping roles in blood clotting, fibrinolysis, the inflammatory response, cellular and matrix interactions and wound healing (Mosesson 2005). The Fbg binding properties of Staphylococcus aureus (O'Neill et al. 2008), Streptococcus suis (Bonifait et al. 2008) and $C$. diphtheriae (Gomes et al. 2009, Sabbadini et al. 2010) allow them to attach to each other through Fbg-mediated cross-bridging, contributing to biofilm production. The ability of C. striatum strains to bind to Fbg was also demonstrated in the present study. In addition to the ability to form biofilms directly on hydrophilic and hydrophobic abiotic surfaces, C. striatum also produced biofilms on Fbg-associated "conditioning films". Compared with the formation of biofilms on the uncoated polystyrene surfaces, the Fbg-coated surfaces showed enhanced biofilm formation by the C. striatum 1987/I-MDR strain, which was responsible for a previous nosocomial outbreak. The enhancement occurred at a typical in vivo concentration of Fbg in blood plasma of approximately $2.5 \mathrm{mg} / \mathrm{mL}$. Therefore, the expression of Fbg-binding adhesins at different levels may be implicated in biofilm formation on "conditioning films" by C. striatum strains, as has been previously reported for $S$. suis (Bonifait et al. 2008).

In conclusion, $C$. striatum may form biofilms in vivo by an adherent biofilm mode of growth in vitro, as was demonstrated on hydrophilic and hydrophobic abiotic surfaces, including polyurethane catheters. The affinity of C. striatum for human Fbg was determined to be an additional potential virulence trait of this organism. In addition to its multi-resistance to antimicrobial agents used in therapy, the ability to produce a "conditioning film" may contribute to the establishment and dissemination of nosocomial infections caused by this organism, including those in patients with indwelling medical devices.

Thus, C. striatum strains capable of forming biofilms may be selected under antibiotic pressure, or conversely, C. striatum may acquire resistance to multiple drugs within biofilm communities. In either event, the high colonising capacity of $C$. striatum combined with its resistance to multiple drugs will contribute to the survival and further dissemination of this organism in the hospital setting.

\section{REFERENCES}

Al Akhrass F, Al Wohoush I, Chaftari AM, Reitzel R, Jiang Y, Ghannoum M, Tarrand J, Hachem R, Raad I 2012. Rhodococcus bacteremia in cancer patients is mostly catheter related and associated with biofilm formation. PLOS ONE 7: e32945.

Baio PVP, Mota HF, Freitas AD, Gomes DLR, Ramos JN, Sant'Anna LO, Souza MC, Camello TCF, Hirata Jr R, Vieira VV, MattosGuaraldi AL 2013. Clonal multidrug-resistant Corynebacterium striatum within a nosocomial environment, Rio de Janeiro, Brazil. Mem Inst Oswaldo Cruz 108: 23-29.

Boltin D, Katzir M, Bugoslavsky V, Yalashvili I, Brosh-Nissimov T, Fried M, Elkayam O 2009. Corynebacterium striatum - a classic pathogen eluding diagnosis. Eur J Intern Med 20: 49-52.

Bonifait L, Grignon L, Grenier D 2008. Fibrinogen induces biofilm formation by Streptococcus suis and enhances its antibiotic resistance. Appl Environm Microbiol 74: 4969-4972.

Brown MRW, Williams P 1985. The influence of environment on envelope properties affecting survival of bacteria in infections. Annu Rev Microbiol 39: 527-556.

Camello TCF, Mattos-Guaraldi AL, Formiga LCD, Marques EA 2003. Nondiphtherial Corynebacterium species isolated from clinical specimens of patients in a university hospital, Rio de Janeiro, Brazil. Braz J Microbiol 34: 39-44.

Campanile F, Carretto E, Barbarini D, Grigis A, Falcone M, Goglio A, Venditti M, Stefani S 2009. Clonal multidrug-resistant Corynebacterium striatum strains, Italy. Emerg Infect Dis 15: 75-78.

Costerton JW, Veeh R, Shirtliff M 2003. The application of biofilm science to the study of and control of chronic bacterial infections. $J$ Clin Inv 112: 1446-1477.

Dooley DP, Garcia A, Kelly JW, Longfield RN, Harrison L 1996. Validation of catheter semiquantitative culture technique for nonstaphylococcal organisms. J Clin Microbiol 34: 409-412.

Fernández-Ayala M, Nan DN, Fariñas MC 2001. Vertebral osteomyelitis due to Corynebacterium striatum. Am J Med 111: 167.

Gomes DL, Martins CA, Faria LM, Santos LS, Santos CS, Sabbadini PS, Souza MC, Alves GB, Rosa AC, Nagao PE, Pereira GA, Hirata Jr R, Mattos-Guaraldi AL 2009. Corynebacterium diphtheriae as an emerging pathogen in nephrostomy catheter-related infection: evaluation of traits associated with bacterial virulence. J Med Microbiol 58: 1419-1427.

Gomes DL, Peixoto RS, Barbosa EA, Napoleão F, Sabbadini PS, dos Santos KR, Mattos-Guaraldi AL, Hirata Jr R 2013. SubMICs of penicillin and erythromycin enhance biofilm formation and hydrophobicity of Corynebacterium diphtheriae strains. J Med Microbiol 62: 754-760.

Kwaszewska AK, Brewczyńska A, Szewczyk EM 2006. Hydrophobicity and biofilm formation of lipophilic skin corynebacteria. Pol J Microbiol 55: 189-193.

Lee HW, Koh YM, Kim J, Lee JC, Lee YC, Seol SY, Cho DT, Kim J 2008. Capacity of multidrug-resistant clinical isolates of Acinetobacter baumannii to form biofilm and adhere to epithelial cell surfaces. Clin Microbiol Infect 14: 49-54.

Lembke C, Podbielski A, Hidalgo-Grass C, Jonas L, Hanski E, Kreikemeyer B 2006. Characterization of biofilm formation by clinically relevant serotypes of group A streptococci. Appl Environm Microbiol 72: 2864-2875.

Leonard RB, Nowowiejski DJ, Warren JJ, Finn DJ, Coyle MB 1994. Molecular evidence of person-to-person transmission of a pigmented strain of Corynebacterium striatum in intensive care units. J Clin Microbiol 32:164-169. 
Maki DG, Weise CE, Sarafin HW 1977. A semi-quantitative culture method for identifying intravenous-catheter-related infection. $N$ Engl J Med 296: 1305-1309.

Martinez-Martinez L, Suarez AI, Winstanley J, Ortega MC, Bernard K 1995. Phenotypic characteristics of 31 strains of Corynebacterium striatum isolated from clinical samples. J Clin Microbiol 33: $2458-2461$

Martins CAS, Faria LMD, Souza MC, Camello TCF, Velasco E, Hirata Jr R, Thuler LCS, Mattos-Guaraldi AL 2009. Microbiological and host features associated with corynebacteriosis in cancer patients: a five-year study. Mem Inst Oswaldo Cruz 104: 905-913.

Mattos-Guaraldi AL, Cappelli EA, Previato JO, Formiga LC, Andrade AF 1999a. Characterization of surface saccharides in two Corynebacterium diphtheriae strains. FEMS Microbiol Lett 170: 159-166.

Mattos-Guaraldi AL, Formiga LC 1991. Relationship of biotype and source to the hemagglutination and adhesive properties of $\mathrm{Co}$ rynebacterium diphtheriae. Braz J Med Biol Res 24: 399-406.

Mattos-Guaraldi AL, Formiga LC, Andrade AF 1999b. Cell surface hydrophobicity of sucrose fermenting and nonfermenting $\mathrm{Co}$ rynebacterium diphtheriae strains evaluated by different methods. Curr Microbiol 38: 37-42.

Moore K, Hall V, Paull A, Morris T, Brown S, McCulloch D, Richardson MC, Harding KG 2010. Surface bacteriology of venous leg ulcers and healing outcome. J Clin Pathol 63: 830-834.

Mosesson MW 2005. Fibrinogen and fibrin structure and functions. $J$ Thromb Haemost 3: 1894-1904.

O’Toole G, Kaplan HB, Kolter R 2000. Biofilm formation as microbial development. Annu Rev Microbiol 54: 49-79.

Oliva A, Belvisi V, Iannetta M, Andreoni C, Mascellino MT, Lichtner M, Vullo V, Mastroianni CM 2010. Pacemaker lead endocarditis due to multidrug-resistant Corynebacterium striatum detected with sonication of the device. J Clin Microbiol 48: 4669-4671.

Olson ME, Ceri H, Morck DW, Buret AG, Read RR 2002. Biofilm bacteria: formation and comparative susceptibility to antibiotics. Can J Vet Res 66: 86-92.

O’Neill E, Pozzi C, Houston P, Humphreys H, Robinson DA, Loughman A, Foster TJ, O'Gara JP 2008. A novel Staphylococcus aureus biofilm phenotype mediated by the fibronectin-binding proteins, FnBPA and FnBPB. J Bacteriol 190: 3835-3850.

Otsuka Y, Ohkusu K, Kawamura Y, Baba S, Ezaki T, Kimura S 2006. Emergence of multidrug-resistant Corynebacterium striatum as a nosocomial pathogen in long-term hospitalized patients with underlying diseases. Diagn Microbiol Infect Dis 54: 109-114.

Rao RS, Karthika RU, Singh SP, Shashikala P, Kanungo R, Jayachandran S, Prashanth K 2008. Correlation between biofilm production and multiple drug resistance in imipenem resistant clinical isolates of Acinetobacter baumannii. Indian J Med Microbiol 26: 333-337.
Renom F, Garau M, Rubí M, Ramis F, Galmés A, Soriano JB 2007. Nosocomial outbreak of Corynebacterium striatum infection in patients with chronic obstructive pulmonary disease. J Clin Microbiol 45: 2064-2067.

Rice SA, Tan CH, Mikkelsen PJ, Kung V, Woo J, Tay M, Hauser A, McDougald D, Webb JS, Kjelleberg S 2009. The biofilm life cycle and virulence of Pseudomonas aeruginosa are dependent on a filamentous prophage. ISME J 3: 271-282.

Rigdon RH 1970. Hemolysis associated with plastics - A histopathologic study with polyurethane. J Biomed Mater Res 4: 57-71.

Rufael DW, Cohn SE 1994. Native valve endocarditis due to Corynebacterium striatum: case report and review. Clin Infect Dis 19: 1054-1061.

Russell AD, Russell NJ 1995. Biocides: activity, action and resistance. Symp Soc Gen Microbiol 53: 327-365.

Rutala WA, Weber DJ, Healthcare Infection Control Practices Advisory Committee (HICPAC) 2008. Guidelines for disinfection and sterilization in healthcare facilities, 2008, Centers for Disease control and Prevention, Atlanta, 158 pp.

Rzhepishevska O, Hakobyan S, Ruhal R, Gautrot J, Barberoc D, Ramstedt M 2013. The surface charge of anti-bacterial coatings alters motility and biofilm architecture. Biomater Sci 1: 589-602.

Sabbadini PS, Genovez MRN, da Silva CF, Adelino TLN, dos Santos CS, Pereira GA, Nagao PE, Dias AASO, Mattos-Guaraldi AL, Hirata Jr R 2010. Fibrinogen binds to nontoxigenic and toxigenic Corynebacterium diphtheriae strains. Mem Inst Oswaldo Cruz 105: 706-711.

Scholle DA 2007. Spontaneous joint infection with Corynebacterium striatum. J Clin Microbiol 45: 656-658.

Soriano F, Huelves L, Naves P, Rodríguez-Cerrato V, del Prado G, Ruiz V, Ponte C 2009. In vitro activity of ciprofloxacin, moxifloxacin, vancomycin and erythromycin against planktonic and biofilm forms of Corynebacterium urealyticum. J Antimicrob Chemother 63: 353-356.

Soriano F, Ponte C, Galiano MJ 1993. Adherence of Corynebacterium urealyticum (CDC group D2) and Corynebacterium jeikeium to intravascular and urinary catheters. Eur J Clin Microbiol Infect Dis 12: 453-456.

Stepanovic S, Vukovic D, Davic I, Savic B, Svabic-Vlahovic M 2000. A modified microtiter-plate test for quantification of staphylococcal biofilm formation. J Microb Meth 40: 175-179.

Stewart PS, Costerton JW 2001. Antibiotic resistance of bacteria in biofilms. Lancet 358: 135-138.

Tarr PE, Stock F, Cooke RH, Fedorko DP, Lucey DR 2003. Multidrug resistant Corynebacterium striatum pneumonia in a heart transplant recipient. Transplant Infect Dis 5: 53-58.

Weiss K, Labbé AC, Laverdière M 1996. Corynebacterium striatum meningitis: case report and review of an increasingly important Corynebacterium species. Clin Infect Dis 23: 1246-1248. 